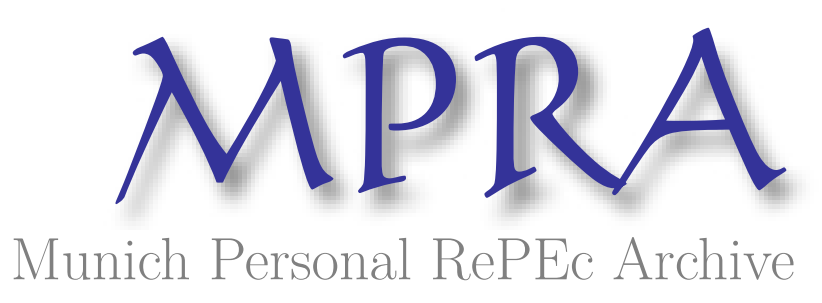

\title{
Elasticities of Substitution and Complementarity
}

Stern, David I

n.a.

31 December 2008

Online at https://mpra.ub.uni-muenchen.de/12454/

MPRA Paper No. 12454, posted 01 Jan 2009 13:11 UTC 


\title{
Elasticities of Substitution and Complementarity
}

December 2008

\author{
David I. Stern \\ 19/30 Watson Street, Turner, ACT 2612, AUSTRALIA \\ E-mail: sterndavidi@yahoo.com
}

\begin{abstract}
This paper develops a classification scheme of the many different definitions of elasticities of substitution and complementarity in the production case based on duality, gross and net substitution, elasticity type, and four different basic concepts of substitution and complementarity. The classic Berndt-Wood dataset is used to show how the various elasticities differ. This variation is considerable and shows that the correct elasticity should be used for the intended purpose - there is no one true elasticity of substitution. The paper also reintroduces and clarifies Pigou's contributions to the debate on the elasticity of substitution after seventy years of obscurity in which they have not been cited.
\end{abstract}

JEL Codes: B21, D24

Keywords: Microeconomics, history of economic thought, production, substitution, elasticity Running Title: Elasticities of Substitution and Complementarity 


\section{Introduction}

In the more than seventy five years since Hicks (1932) introduced the elasticity of substitution (ES) many variations and generalizations of this pivotal concept have been developed, but there is still much confusion about what is measured by the various forms of the ES. This has not been helped by frequent shifts in nomenclature and terminology and by the fact that various pivotal contributions languished in obscurity before their results were sometimes rediscovered. In response to this confusion, some have argued that particular elasticities are the true elasticity of substitution (e.g. Blackorby and Russell 1989 2007; Kim. 2000). The primary purpose of this paper is to present a synthesis of the various existing classifications of the elasticity of substitution in the production case without advocating the superiority of one variant or the other. Instead, I emphasize that each might be useful for a particular purpose.

The original purpose of the ES, introduced by Hicks (1932), was to determine how the factor shares of income change as the ratio of the factors changes. Lerner (1933) reformulated the ES in the format adopted by Hicks and Allen (1934a) defining the elasticity of substitution as the reciprocal of the degree to which the substitutability of two factors, that is the marginal rate of substitution, varies as the ratio of the two inputs varies and output is held constant. Hicks and Allen (1934a) wrote:

"The curvature of the indifference curve describes the same property as the "rate of increase of the marginal rate of substitution". But to take either as our measure without correction for units would be impossible... A measure free from this objection fortunately now lies ready to hand. It is the elasticity of substitution, when defined in a 
way analogous to that used by Mrs Robinson and Mr Lerner. Applied to this problem it becomes:

Relative increase in the proportion possessed of the two commodities $(\mathrm{Y} / \mathrm{X})$ / relative increase in the marginal rate of substitution of $\mathrm{Y}$ for $\mathrm{X}$.

when a small amount of $\mathrm{Y}$ is substituted for $\mathrm{X}$, in such a way as to compensate the consumer for his loss (That is to say, it is taken along the indifference curve)... It is... a general measure of substitutability." (58-59).

This statement subtly implied new additional meanings for the ES - a measure of the curvature of the production function, and a measure of substitutability. Hicks and Allen (1934a) went on to discuss the dichotomy of "competitive" and complementary commodities or inputs, which Hicks (1970) renamed q-substitutes and q-complements. ${ }^{1}$ Since Pareto and Edgeworth these concepts had been used to discriminate between commodities and inputs based on the sign of the second derivative of the utility or production function (Hicks and Allen 1934a). An increase in the use of one q-substitute input reduces the marginal product of the other input, while an increase in the use of a q-complement input raises the marginal product of the other input. Hicks and Allen (1934a) sought to banish the q-substitution/q-complementarity dichotomy because it depends on a concept that is unmeasurable in ordinal utility theory. Instead, they proposed that commodities be defined as "competitive" / complementary on the basis of the sign of what they called the 
partial elasticity of complementarity. In one of their many confusing changes of definitions and nomenclature Hicks and Allen renamed this "elasticity of complementarity" as the "partial elasticity of substitution" (Hicks 1936; Allen 1938). ${ }^{2}$ Eventually, this indicator became known as the Allen-Uzawa elasticity of substitution. The new competitive / complementary dichotomy soon became known as the dichotomy between substitutes and complements, which (for net or compensated substitution) can be discriminated between on the basis of the Allen-Uzawa elasticity of substitution. Two inputs are p-substitutes in Hicks (1970) terminology if when the price of one rises the quantity of the other increases and p-complements if the quantity decreases as a result.

Therefore, four different concepts of substitutability emerged from this literature:

1. The effect on relative income shares of a shift in the quantities of inputs, $x$, used, measured as:

$\sigma_{i j}=\frac{\partial \ln \left(p_{i} / p_{j}\right)}{\partial \ln \left(x_{j} / x_{i}\right)}$

where $\mathrm{p}$ are the prices of the inputs $\mathrm{x}$. The inverse of this derivative can be used for changes in prices. Various sets of variables may be held constant. Lerner's (1933)

1 Various other homonyms have been used including aiding (mesayy'im in Hebrew) and competing (mitharim) ( Blumenthal et al. 1971), cooperant and rival (Hicks 1936) and complementary and anti-complementary (e.g. Hirschleifer and Hirschleifer 1997).

2 Hicks (1970) later reintroduced the term "elasticity of complementarity" to mean something else again, which is where the name has stuck. Different (and quickly abandoned) definitions of competitive and complementary commodities yet again are discussed in Allen (1934). 
proposal to hold the quantities of output and the other inputs constant is not appropriate if we want to look at the optimal response to a change in the factor ratio as the quantities of other inputs and the level of output might change when moving from one optimum to another.

2. The difficulty of substitution or curvature of the production function. The quotation in the above suggests:

$\sigma_{i j}=\left.\frac{\partial \ln \left(p_{i} / p_{j}\right)}{\partial \ln \left(x_{j} / x_{i}\right)}\right|_{y}$

where $y$ is output, which is held constant. Assuming that the quantities of other inputs are also held constant in the $\mathrm{m}>2$ case, this is Allen and Hicks (1934b) and Lerner's) (1933) elasticity of substitution. This is now known as the Hicks or Direct ES. Usually though it is defined as the reciprocal of (2).

\section{3. p-substitutes and p-complements:}

$\sigma_{i j}=\frac{1}{S_{j}} \frac{\partial \ln x_{i}}{\partial \ln p_{j}}$

where $S_{j}$ is the cost share of input $\mathrm{j}$. This is the share-weighted cross-price elasticity, which in the case of net substitution is the Allen-Uzawa ES. p-complementarity and psubstitutability are behavioural labels rather than technical ones, though they are of course determined by the combination of the technical parameters of the production function and cost-minimising or profit-maximising behaviour. 


\section{4. q-substitutes and q-complements:}

$$
\sigma_{i j}=\frac{1}{S_{j}} \frac{\partial \ln p_{i}}{\partial \ln x_{j}}
$$

which is the share-weighted second logarithmic derivative of the production or utility function.

Samuelson (1974) found four definitions of substitutability and complementarity in the consumption case in the existing literature. These correspond to my definitions 2 and 4 , and gross and net versions of my definition 3. Samuelson develops two further measures of complementarity in the consumption case which I will ignore as this paper only discusses the production case. But it is interesting that my definition 1 - the original purpose of the ES - is not even defined by Samuelson as a type of substitution.

There are three further ways of classifying elasticities of substitution:

a. Optimizing and non-optimizing behavior. Movement along an isoquant of the production function as the ratio of two inputs changes as in equation (2) holds the quantities of all other inputs constant, but optimizing behavior in response to a change of the price of an input in general requires the quantities of all inputs to change. Some definitions of elasticities of substitution such as that defined by equation (2) hold other input quantities constant and some such as the well-known Allen-Uzawa elasticity of substitution based on equation (3) do not. 
b. Gross and net substitution. Similarly an optimal response might require changing the quantity of output, which is termed gross substitution, as opposed to equation (2), which holds it constant, which is termed net substitution. Gross elasticities of substitution have been devised as discussed in the following sections.

c. Primal and dual elasticities. We can classify elasticities of substitution according to whether the elasticity in question is derived from the primal production problem or its dual. Indicators of p-substitution and p-complementarity (3) are most obviously derived from the dual problem while indicators of q-substitution and q-complementarity (4) are most obviously derived from the primal problem. But there are also primal (where quantities of inputs change and dual (where prices of inputs change) elasticities that address the first two definitions of substitution (equations 1 and 2).

In this paper, I develop a classification of the various versions of the ES, which extends Mundlak's (1968) classification, as well as reviewing how the ES evolved, and providing a guide to the appropriate uses of each indicator. The paper also reintroduces and clarifies Pigou's contributions to the debate on the elasticity of substitution after seventy years of obscurity in which they have not been cited.

The following section of the paper presents the classification of the ten elasticities. The third section then provides formulae for each elasticity and gives the historical background of their origination. The fourth section of the paper illustrates the numerical differences between the 
different ES using the classic Berndt and Wood (1975) dataset. The discussion and conclusions discuss possible roots of the common confusions and misunderstandings regarding the ES.

\section{Classification of the Elasticities of Substitution and Complementarity}

Table 1 provides a taxonomy of the objective and demand functions that can be used to derive elasticities of substitution for both the gross and net substitution cases for the primal and dual problems. The profit and cost functions on the right-hand side of the table need no explanation. Their derivatives are the standard gross and net demand functions, which explain the quantity demanded in terms of the prices of inputs and for the net demand functions the quantity of output and for the gross demand function the price of output. Likewise, the related elasticities of substitution including the Allen-Uzawa elasticity derived from the cost function hold the prices

of all other inputs constant apart from those being varied and in the case of the Allen-Uzawa elasticity hold output constant. There is also a similar elasticity derived from the profit function (Hotelling-Lau), which holds the price of output constant. Further related elasticities are listed in Table 2. and discussed below.

Paralleling the objective and demand functions on the right hand side of the table are the primal concepts on the left-hand side. The familiar production function can be generalized for multiple output production by the output distance function (Färe and Primont 1990). Its derivatives are the inverse demand functions that explain prices or shadow prices (Mundlak 1968) as functions of the price of output and the quantities of inputs. The related elasticities of substitution listed in Table 2 will hold the price of output constant and the quantities of all other inputs except those being varied constant. The input distance function (Färe and Primont 1990) defines the distance 
of the input vector from the minimum input requirement isoquant for a given output. The function is defined on output and inputs. If production is technically efficient the distance is equal to one. The derivatives of this function are inverse demand functions relating the shadow prices of inputs to functions of output and input quantities. As can be seen from Table 2, three elasticities are related to the input distance function and its derivatives.

Mundlak (1968) presented a brilliant synthesis of the literature, which appears to have been relatively little read or cited till the mid-1990s. Mundlak's nine long-run elasticities are all on the dual side of Table 1, though he does not use the dual objective functions to derive the elasticities. My own classification builds on Mundlak's by extending it to the primal side of Table 1 and by incorporating the literature since Mundlak. Mundlak (1968) classifies the elasticities as:

1. Two factor, two price

2. Two factor, one price

3. One factor, one price

In the first category, a ratio of factors responds to a ratio of prices - this is the original concept of the ES as in equations (1) and (2). This concept is symmetric so that it does not matter which prices or quantities change in the denominator of the derivative to alter the ratio. However, in an important but forgotten paper ${ }^{3}$ Pigou (1934) pointed out that when there are more than two inputs $(\mathrm{m}>2)$, the two factor, two price class of ES does depend on how the ratio of prices changes, unless further restrictions are made. Without these restrictions the elasticities are not

${ }^{3}$ There are no citations to Pigou's paper in the period 1954-2008 in the ISI Citation Index. 
symmetric to which price or quantity in the denominator changes. This point was rediscovered many years later by Mundlak (1968), Morishima (1967), and Blackorby and Russell (1975). The usual restriction made for the elasticity corresponding to the dual net case is to maintain cost constant yielding McFadden's (1963) shadow elasticity of substitution (first row of Table 2). Though other restrictions are also possible, this is the natural restriction from the point of view of duality theory as now the ES measures movement along an isocost curve of the cost function. In the primal case, Pigou (1934) suggested holding the output quantity constant. But output is already held constant in net q-substitution as it is for net p-substitution. From Table 2 we see that, because net q-substitution is associated with the input distance function, the appropriate additional restriction is holding distance from the production frontier constant. Stern (2008) derives the HES from the input distance function.

Mundlak's second category is the same as the first except the restrictions that result in symmetry of the elasticity are not imposed. Therefore, the factor ratio responds differently depending on which one of the two prices in the price ratio is perturbed. This class includes the Morishima elasticity of substitution, which we can credit Mundlak with independently discovering one year after Morishima (but still 34 years after Pigou discovered its dual discussed below). The third category, which includes the Allen-Uzawa elasticity of substitution, is sometimes called the partial elasticity of substitution, and is defined in terms of derivatives of scalars instead of ratios.

Mundlak also looks at "short-run elasticities" where input quantities are fixed. These correspond to the primal side of Table 1. The three cases now are two price - two factor, two price - one factor, and one price - one factor. Mundlak only discusses the one price, one factor and two 
price, two factor cases. The constant output case of the latter is the HES. My classification given in Table 2 is based on Mundlak's three categories and Table 1. There are ten elasticities, which are described in more detail in section 3 below. ${ }^{4}$

The boxes for both primal and dual gross two price, two factor ES are empty because these elasticities have never been proposed in the literature. A further anomaly is that the HES is usually expressed as $\partial \ln \left(\mathrm{x}_{\mathrm{i}} / \mathrm{x}_{\mathrm{j}}\right) / \partial \ln \left(\mathrm{p}_{\mathrm{j}} / \mathrm{p}_{\mathrm{i}}\right)$ as it was formulated by Robinson (1933) and Lerner (1933) rather than as $\partial \ln \left(\mathrm{p}_{\mathrm{i}} / \mathrm{p}_{\mathrm{j}}\right) / \partial \ln \left(\mathrm{x}_{\mathrm{j}} / \mathrm{x}_{\mathrm{i}}\right)$ as it should be expressed due to its primal nature. Clearly though, Hicks and Allen (1934a) were thinking in terms of the rate of change of the MRS as the factor ratio changes and therefore the latter is really the appropriate formulation. However, tradition treats a greater HES as indicating greater substitutability and this convention is probably locked in. Logically, the original HES should also be called an elasticity of complementarity. To paraphrase Hicks (1970 296), it now seems to be way too late to develop a logical terminology.

An implication of Table 1 is that all the elasticities should be derivable from the relevant functions in that table. The original derivations in the literature sometimes do not exploit these functions. In the next section of the paper I present these more systematic formulae.

The various elasticities are expected to have fairly well defined quantitative relations (Frondel and Schmidt 2002; Kim 2000). The gross dual elasticities should show greater p-

\footnotetext{
${ }^{4}$ Including the constant cost demand functions discussed by Mundlak there are theoretically six more elasticities - but these are likely to see little use.
} 
complementarity than the net elasticities while the gross primal elasticities should show greater q-substitutability. The Morishima type elasticities should show greater p-substitutability and greater q-complementarity than the one price - one factor elasticities. Finally, the SES is more constrained than the other dual elasticities as cost is held constant.

It is important to note that in the two input case $(\mathrm{m}=2)$ all the net ES are equal and all the gross ES are equal. ECs will be the reciprocals of the respective ESs. Under constant returns to scale net and gross elasticities are also equal. Additionally, in the $\mathrm{m}=2$ case inputs must be $\mathrm{p}$ substitutes (Hicks and Allen 1934a) or non-substitutable (and q-complements). ${ }^{5}$ Therefore, most of the discussion in the paper is only really relevant when $m>2$ and/or there are non-constant returns to scale.

${ }^{5}$ Clearly two inputs could be q-substitutes but it seems that then the isoquants must be concave to the origin so that there is no economic region (defined as the input combinations for which the marginal products are all non-negative) and only one input is used. For multiple inputs convex isoquants can be compatible with some inputs being q-substitutes though in the presence of qsubstitutes the isoquants need not be convex. 


\section{Description of the Elasticities of Substitution and Complementarity}

\subsection{Primal Elasticities}

\subsubsection{Two Ratios: Hicks (Direct) Elasticity of Substitution}

The HES or direct ES between two inputs was derived from the production function by Hicks and Allen (1934b) and simplified by McFadden (1963). As shown by Stern (2008) we can also derive this elasticity from the distance function, which as required holds output constant implying movement along an isoquant. This derivation is similar to the derivation of the SES from the cost function. The SES is defined for movement along an isocost line. Likewise, the HES can be defined for movement along a constant distance line. Holding distance constant is a desirable condition. When distance is unity production is efficient. Deviations from unity either imply inefficiency or impossibility. For my suggested primal definition where the numerator of the elasticity is the ratio of prices:

$H E S_{i j}=\frac{-\frac{D_{i i}}{D_{i} D_{i}}+2 \frac{D_{i j}}{D_{i} D_{j}}-\frac{D_{j j}}{D_{j} D_{j}}}{\frac{1}{D_{i} x_{i}}+\frac{1}{D_{j} x_{j}}}$

where $\mathrm{D}$ is the distance function. The formal derivation is given in the Appendix.

It is well-known that if HES>1 (The traditional ES version of the HES) then the isoquant cuts the axes so that neither input is essential, while for $\mathrm{HES}=0$ the isoquant is a right angle, with intermediate values corresponding to essential but substitutable inputs. 


\subsubsection{Ratio and Scalar}

\subsubsection{Gross: Pigou Elasticity of Complementarity}

Following his observation that in general the elasticity of substitution is asymmetric, Pigou (1934) formulated two special cases where various variables are assumed to remain constant as substitution proceeds. The first, based on the suggestion of Hicks himself, holds output quantity and the quantities of all the other inputs constant and became known as the direct or Hicks elasticity of substitution (HES). This would not be a useful indicator of how factor income shares change in response to factor ratio changes as in general the quantities of the other inputs will also be changing. Another formulation suggested by Pigou has output variable and all factors apart from one of the two in the ratio under consideration held constant. This elasticity is then shown to be a simple function of the own price and cross-price elasticity. This "Pigou elasticity of complementarity" ${ }^{6}$ is given by:

$$
P E C_{i j}=\frac{\partial \ln p_{i}\left(p_{y}, x\right)}{\partial \ln x_{i}}-\frac{\partial \ln p_{j}\left(p_{y}, x\right)}{\partial \ln x_{i}}
$$

The PEC measures how the input price ratio changes as the input quantity ratio changes with all other input quantities and the output price held constant but the output quantity and all input prices varying. The fixed output price implies profit maximisation and, therefore, the elasticity might be suitable in a macro context with immobile domestic factors of production and international output prices. The PEC is the dual of a gross version of Morishima's elasticity (the FRES) and like the MES and the MEC, discussed below, is asymmetric. The PEC does not

\footnotetext{
${ }^{6}$ Hicks (1936) calls this the "Pigou elasticity of partial productivity".
} 
discriminate between q-substitutes and q-complements in the $m>2$ case. ${ }^{7}$ That is the role of the Antonelli and Hicks ECs.

\subsubsection{Net: Morishima Elasticity of Complementarity}

Blackorby and Russell (1981) and Kim (2000) proposed a Morishima elasticity of complementarity based on the distance function. This is a net version of the PEC. The formula is:

$$
M E C_{i j}=\frac{\partial \ln \left(D_{i}(y, x) / D_{j}(y, x)\right)}{\partial \ln \left(x_{j} / x_{i}\right)}=\frac{\partial \ln p_{i}(y, x)}{\partial \ln x_{j}}-\frac{\partial \ln p_{j}(y, x)}{\partial \ln x_{j}}
$$

The MEC is, therefore, the difference between two price elasticities based on the inverse demand functions derived from the input distance function and is asymmetric. The elasticity shows how the price ratio changes as one of the inputs in a fixed input ratio changes under the assumption of cost-minimisation holding all other inputs and output constant. It is impossible for only one input to change and for output to be held constant, unless distance is changing. And this is exactly what must be the case for the MEC (and the AEC). Stern's (2008) version of the HES applies the constant distance restriction to the MEC in the same way that the SES applies a constant cost condition to the MES. If we assume that producers optimize and attempt to be efficient, net qsubstitutability will only be relevant if the free-disposal assumption is violated.

\subsubsection{Two Scalars}

\subsubsection{Gross: Hicks Elasticity of Complementarity}

This was the first of the elasticities of complementarity (in the modern sense) to be formally identified as such when Hicks (1970) introduced the concept. The idea was that the HEC would

\footnotetext{
${ }^{7}$ Similarly the Morishima and factor ratio ES's do not discriminate between p-substitutes and
} 
be dual to the Allen-Uzawa ES and would reflect the change in the price ratio for a change in the input ratio holding the quantities of the other inputs constant and the output price constant. It can be shown (Sato and Koizumi 1973), therefore, to be:

$H E C_{i j}=\frac{f(x) f_{i j}(x)}{f_{i}(x) f_{j}(x)}=\frac{f}{f_{j} x_{j}} \frac{\partial \ln p_{i}\left(p_{y}, x\right)}{\partial \ln x_{j}}$

where $\mathrm{f}$ is the production function. The HEC is also equal to the cross quantity elasticity of the inverse demand function divided by the product share of the input whose quantity is changing. The HEC discriminates between gross q-substitutes and complements. The elasticity is positive for q-complements and negative for q-substitutes.

Syrquin and Hollender (1982) and Blackorby and Russell (1981) both pointed out that under non-constant returns to scale it is not the exact dual of the AES. It is, in fact, the dual of the gross version of the AES - the HLES (Kim 2000). An interesting conclusion of Hicks (1970) and Sato and Koizumi (1973) is that in the two input case the HEC and AES must take the same sign. Assuming that we are in the economic region of the production function, in the two input case the two inputs must be p-substitutes and therefore they must also be q-complements. The situation is a bit more complex for the $\mathrm{n}>2$ case.

\subsubsection{Net: Antonelli Elasticity of Complementarity}

This elasticity was originally proposed by Blackorby and Russell (1981) as the true dual of the AES under non-constant returns to scale. Kim (2000) appears to develop this elasticity independently, calling it the Antonelli Elasticity of Complementarity. This partial elasticity of

complements. 
complementarity is derived from the input distance function, which holds output constant and it keeps all other inputs except the one that is perturbed constant. The AEC discriminates between net q-complements and q-substitutes being positive and negative respectively. The AEC is the dual to the AES and the HEC is the dual to the gross version of the AES (FRES).

$A E C_{i j}=\frac{D(y, x) D_{i j}(y, x)}{D_{i}(y, x) D_{j}(y, x)}=\frac{1}{S_{j}} \frac{\partial \ln p_{i}(y, x)}{\partial \ln x_{j}}$

where $S_{y}$ is the cost share of $x_{j}$. As in the case of the MEC, distance is not held constant.

\subsection{Dual Elasticities}

\subsubsection{Two Ratios: Shadow Elasticity of Substitution}

McFadden (1963) introduced the shadow elasticity of substitution, which is defined in terms of the cost function, C. It is derived by applying a constant cost restriction to the Morishima Elasticity of Substitution resulting in the symmetry of the elasticity to changes in different prices. It, therefore, measures the curvature of the cost function along an isocost curve.

$$
S E S_{i j}=\frac{-\frac{C_{i i}}{C_{i} C_{i}}+2 \frac{C_{i j}}{C_{i} C_{j}}-\frac{C_{j j}}{C_{j} C_{j}}}{\frac{1}{C_{i} p_{i}}+\frac{1}{C_{j} p_{j}}}
$$

where the subscripts on $\mathrm{C}$ represent derivatives, following the usual conventions. Its duality to the HES (5) is obvious.

\subsubsection{Ratio and Scalar}

\subsubsection{Gross: Factor Ratio Elasticity of Substitution}

Davis and Shumway (1996) introduce a generalisation of the Morishima ES - a generalised factor ratio elasticity of substitution (FRES) that nests the MES as a special case under the 
assumption of cost minimisation with output held constant and all other input prices constant. This generalisation was, already presented by Mundlak (1968). However, Davis and Shumway (1996) present the general formula:

$F R E S_{i j}=\frac{\partial \ln x_{j}(w, p)}{\partial \ln p_{i}}-\frac{\partial \ln x_{i}(w, p)}{\partial \ln p_{i}}$

where $\mathrm{w}$ is a variable on which the demand function is conditioned, which could include cases beyond those examined by Mundlak (1968). As in the specific case of the MES the FRES is asymmetric. Davis and Shumway (1996) show that under homotheticity the MES also provides correct predictions for shifts in factor ratios for cases other than cost minimisation. But in the general case, specific net and gross versions of the FRES must be used. I use the term FRES to refer to (11) where $\mathrm{w}$ is the price of output and the elasticities are, therefore, derived from the profit function. This specific elasticity is discussed by Blackorby et al. (2007) under the name “Morishima Gross Elasticity of Substitution'.

\subsubsection{Net: Morishima Elasticity of Substitution}

Following McFadden's (1963) introduction of the SES, the next major development in the history of the elasticity of substitution was the independent "(re-)discovery" by Morishima (1967) and Blackorby and Russell (1975) of the Morishima ES (MES). This was a clear result of the introduction of widespread use of dual cost functions. Blackorby and Russell (1975) evaluate the following derivative:

$$
M E S_{i j}=\frac{\partial \ln \left(C_{i}(p, y) / C_{j}(p, y)\right)}{\partial \ln \left(p_{j} / p_{i}\right)}
$$

as according to Shephard's Lemma the derivative of the cost function is equal to the optimal factor input. This, therefore, is exactly Robinson's (1933) notion of the elasticity of the change in 
the input ratio with respect to the price ratio holding output constant and letting all other inputs adjust optimally by holding prices constant. Blackorby and Russell (1989) show that for a change in $\mathrm{p}_{\mathrm{i}}$ this elasticity is given by:

$$
M E S_{i j}=\frac{p_{i}\left(C_{i j}(y, p) C_{i}(y, p)-C_{i i}(y, p) C_{j}(y, p)\right)}{C_{i}(y, p) C_{j}(y, p)}=\frac{\partial \ln x_{j}(y, p)}{\partial \ln p_{i}}-\frac{\partial \ln x_{i}(y, p)}{\partial \ln p_{i}}
$$

The elasticity is asymmetric so that $M E S_{\mathrm{ij}} \neq M E S_{\mathrm{ji}}$. Blackorby and Russell (1989) further showed that the MES was a sufficient statistic for predicting changes in income shares, was constant for the CES production function, and correctly determined non-substitutability in some cases they examined. A measure such as this where all inputs change optimally is appropriate obviously for modelling changes in cost shares if there is cost minimising behaviour and all inputs are variable.

\subsubsection{Two Scalars}

\subsubsection{Gross: Hotelling-Lau Elasticity of Substitution}

A gross version of the AES was introduced by Lau (1978). Bertoletti (2005) calls this the Hotelling-Lau ES and demonstrates the duality relation between this and the HEC. This elasticity can discriminate between gross p-substitutes and complements being positive in the former case and negative in the latter. The formula is:

$H L E S_{i j}=-\frac{\Pi\left(p_{y}, p\right) \Pi_{i j}\left(p_{y}, p\right)}{\Pi_{i}\left(p_{y}, p\right) \Pi_{j}\left(p_{y}, p\right)}=-\frac{\Pi}{p_{j} x_{j}} \frac{\partial \ln x_{i}\left(p_{y}, p\right)}{\partial \ln p_{j}}$

where $\Pi$ is the profit function, $p_{y}$ is the price of output, and the subscripts indicate derivatives.

The negative sign is due to the fact that input quantities and their profit shares are negative in the profit function context. 


\subsubsection{Net: Allen-Uzawa Elasticity of Substitution}

Finally, we reach the most commonly used of all the elasticities of substitution. Hicks and Allen (1934a; 1934b) called the HES the elasticity of substitution while introducing a new concept: the "elasticity of complementarity". But Hicks (1936) changes the name of this new elasticity of complementarity to the "partial elasticity of substitution" and this is how it appears in Allen (1938). The term "partial elasticity of substitution" is justifiable as it measures the impact on one quantity of one price changing rather than the connection between an input ratio and a price ratio measured by the elasticity of substitution. Later, the partial elasticity of substitution became known as the Allen elasticity of substitution (AES) and it became popular to use the AES to classify inputs as p-complements or p-substitutes. Allen $(1934 ; 1938)$ gave the formula based on a production function but Uzawa's (1962) dual formulation is used in most of the literature, especially following the classic paper by Berndt and Wood (1975). The Uzawa (1962) formulation is given by:

$$
A E S_{i j}=\frac{C(y, p) C_{i j}(y, p)}{C_{i}(y, p) C_{j}(y, p)}=\frac{1}{S_{j}} \frac{\partial \ln x_{i}(y, p)}{\partial \ln p_{j}}
$$

where $\mathrm{C}$ is the cost function with input prices $\mathrm{p}$ and output $\mathrm{y}$ as independent variables and subscripts refer to derivatives of the cost function. $S_{j}$ is the share of input $j$ in total cost. As pointed out by Blackorby and Russell (1989), the same information is given by the net crossprice elasticity. This is obvious in Hicks and Allen (1934a). The reason that the AES was introduced was because in 1934 "cross-price elasticity of demand" meant the Marshallian elasticity. Hicks and Allen were introducing the notion of the net or Hicksian elasticity. ${ }^{8}$ So these one factor, one-price elasticities are all in a sense historical artefacts. However, Allen (1938)

\footnotetext{
${ }^{8}$ Slutsky independently developed these ideas in 1915 (Samuelson 1974).
} 
does not mention a general elasticity of substitution for the multiple input case and only describes these partial elasticities of substitution. Therefore, among the majority of economists the belief arose that the AES was the elasticity of substitution.

\section{Numerical Analysis}

The purpose of this section is to give the reader an intuitive grasp of the differences between the ten elasticities by computing them for a single data set. Following Kim (2000), I have chosen to use the classic Berndt and Wood (1975) data set to allow comparability with previous studies.

As computation of some of the elasticities requires returns to scale parameters, we cannot use Berndt and Wood's (1975) original estimates to derive all the elasticities. Instead, I estimate three cost share equations and the cost function itself imposing homogeneity in input prices and symmetry of cross-product parameters. The parameters of the levels terms in translog functions depend on the indexing of the series while the parameters of the quadratic terms are invariant to such transformations (Hunt and Lynk 1993; Stern 1995). The mean of all the logarithmic and trend variables in the various share equations are deducted before estimating the model. I then compute the elasticities at the mean where all the explanatory variables are zero. The AES is computed for the sample mean using:

$$
A E S_{i i}=\frac{\beta_{i i}+\beta_{i}^{2}-\beta_{i}}{\beta_{i}^{2}} \quad A E S_{i j}=\frac{\beta_{i j}+\beta_{i} \beta_{j}}{\beta_{j}^{2}}
$$

All the other elasticities are then derived using the formulae in the Appendix. 
Table 3 presents the elasticities for all input combinations. Looking first at the Allen elasticities of substitution (AES), they are, as expected, of similar magnitude and the same sign as the estimates provided by Berndt and Wood (1975). They indicate that energy and capital and materials and capital are net p-complements but that the other input combinations are net $\mathrm{p}$ substitutes.

As the output elasticity of cost is less than one, in most cases the HLES and AES have opposite signs. Capital and energy are net p-complements but gross p-substitutes. The gross elasticities, do though show somewhat more complementarity than the net do. The asymmetric dual elasticities (MES and FRES) indicate a relation of net p-substitution and gross pcomplementarity. Thompson and Taylor (1995) report almost equal Morishima elasticities of 0.31 and 0.32 for capital and energy, which are mid-way between the two estimates that I find. The shadow elasticities of substitution for all input combinations are less than unity indicating limited substitution possibilities.

While the ES should show more p-complementarity in the gross case than the net case the EC should show less q-complementarity in the gross case (Kim 2000). As expected the HEC shows less q-complementarity than the AEC. The difference between the two estimates is not very large, however. While Kim (2000) finds using production function estimates that all the inputs are q-complements according to the AEC, my estimates derived from the cost function show a mixed picture. Materials are q-complements with all other inputs and the energy and capital pair are also q-complements. But the other input combinations are q-substitutes. Only the capitalenergy elasticity is similar - Kim's (2000) estimates are 6.22 for the HEC and 10.13 for the 
AEC. Kim's (2000) results for the Hicks elasticity of complementarity show q-complementarity only between capital and labor and capital and energy with all other input combinations being qsubstitutes. My results are quite different to his and very similar to my AEC results.

The MEC and PEC show all inputs to be q-complements with the exception of labor-capital. Apart from this elasticity, neither the PEC nor the MEC show a large degree of asymmetry, which is similar to Thompson and Taylor's (1995) results for the MES. Again the Pigou EC should also show less q-complementarity than the MEC. In this case the picture is very mixed with some elasticities greater and others smaller.

Finally, the direct or Hicks ES is shown here in elasticity of complementarity form. All inputs are q-complements as is theoretically necessary and all show an elasticity of complementarity of greater than unity, which is equivalent to an elasticity of substitution of less than one. For example, the elasticity of 3.61 for capital and energy corresponds to the traditional elasticity of substitution of 0.28 , which is similar to the SES estimate of 0.38 - all the HES elasticities show a bit less substitutability than the SES. We can also see that the MEC is a reasonable estimate of the HES just as we can see that the MES is a reasonable estimate of the SES for this dataset. However the scalar elasticities are radically different in value.

In conclusion, the ten elasticities vary widely and significantly. It is clearly important to use the correct elasticity for the relevant application. 


\section{Discussion and Conclusions}

As we have seen, there are several different economic concepts of substitution each with an appropriate indicator. However, the general notion of "difficulty of substitution" remains elusive. As explained above, a mistaken belief emerged that the (AES) was intended to measure shifts in cost or income shares, measure the difficulty of substitution, determine whether inputs were complements or substitutes in the $m>2$ case as well as in the $m=2$ case (Blackorby and Russell 1989). But it was not till the 1970s that these misconceptions began to be cleared up. However, misconceptions are still present. For example, criticism of the MES for tending to find that inputs are net substitutes in almost every case (e.g. Frondel and Schmidt 2002) seems misplaced, as it was never intended to be used for this purpose.

The MES does not convey information on whether inputs are p-substitutes or p-complements when $m>2$. The AES, in either a net or gross version (HLES), does provide this information. However, the cross-price elasticity provides the same information and the AES just scales that parameter by one of the cost shares.

When the MES is used mistakenly to classify inputs as p-substitutes or p-complements it tends to classify all inputs as substitutes as the own price elasticity tends to be greater in absolute value than any cross-price elasticities (Frondel and Schmidt 2002). The HES must be non-negative in the economic region of the production function and, therefore, classifies all inputs as substitutes or non-substitutable in the Leontief case. It does not model a behavioural response inherent in the notion of p-substitutes and complements but is instead a statistic describing the production technology. 
Turning to the difficulty of substitution, the HES and SES are the most appropriate indicators in the general case though the various Morishima type elasticities will provide good approximations. De la Grandville (1997) introduces an alternative measure of curvature and points out that the AES does not directly relate to a mathematical notion of curvature or even to the second derivative of the production function. This should be obvious from my discussion so far, as the AES was never intended for this purpose. The HES holds the quantity of the other inputs constant and hence measures the shape of the isoquant. This is a technical notion of substitutability. The AES and MES, though, obviously do not measure the shape of an isoquant.

Another alternative measure of curvature appears in Hicks and Allen (1934b) and is given for three inputs by:

$$
\sigma=\frac{m_{j i} m_{k i}}{x_{i} x_{j} x_{k}} \frac{4}{x_{i}+m_{j i} x_{j}+m_{k i} x_{k}} \begin{array}{ccc}
1 & m_{j i} & m_{k i} \\
\partial m_{j i} / \partial x_{i} & \partial m_{j i} / \partial x_{j} & \partial m_{j i} / \partial x_{j} \\
\partial m_{k i} / \partial x_{i} & \partial m_{k i} / \partial x_{j} & \partial m_{k i} / \partial x_{j}
\end{array} \mid
$$

where $\mathrm{m}_{\mathrm{ij}}$ is the marginal rate of substitution between $\mathrm{x}_{\mathrm{i}}$ and $\mathrm{x}_{\mathrm{j}}$. Hicks and Allen state that this parameter measures the curvature of the indifference or isoquant surface passing through the point. It does not relate to substitution in any particular direction. It is clearly zero for the Leontief function and infinite for the linear isoquant case. It is involved in the computation of the elasticities of substitution and complementarity in their paper but does not appear to have been used on its own as an index of substitutability. 
I believe there are three likely reasons behind some of the confusion concerning the ES. First is the number of different definitions of substitution and complementarity and different purposes of the elasticity of substitution. Hicks and Allen frequently changed definitions and terminologies in the course of a few years leading to much confusion. Second, before the introduction of duality theory, visualising and understanding the relationships involved was harder than it is now and the mathematics involved was relatively hard for the average economist in the 1930s. Furthermore, economics is frequently taught using two input, or two consumption good, examples as these are easy to draw graphically. But, as far as the ES is concerned, the $n>2$ world is fundamentally different from the $n=2$ world. Finally, most economists, like most natural scientists and unlike members of many other social science disciplines, do not generally return to read the original sources or study the history of economic thought too deeply. For example, Pigou's (1934) contribution to this debate went unrecognised since at least the 1950s.

This paper has focused on ten elasticities of substitution for each of the production and consumption cases but pointed to the existence of further elasticities that are not frequently represented in the literature. Many more elasticities are found in Hicks and Allen (1934b). Of course, there are theoretically unlimited numbers of such elasticities each with different subsets of variables held constant while others change. In this regard elasticities should be tailored to specific circumstances. Given this potential diversity, the quest for the elasticity of substitution should end. 


\section{Appendix:}

I computed the sample mean Allen elasticities of substitution from the cost function parameters. The SES, AEC, HEC, HLES, and MES were then computed from the AES and the parameters of the translog cost function. The remaining elasticities were derived from the HEC and AEC according to the following schema:

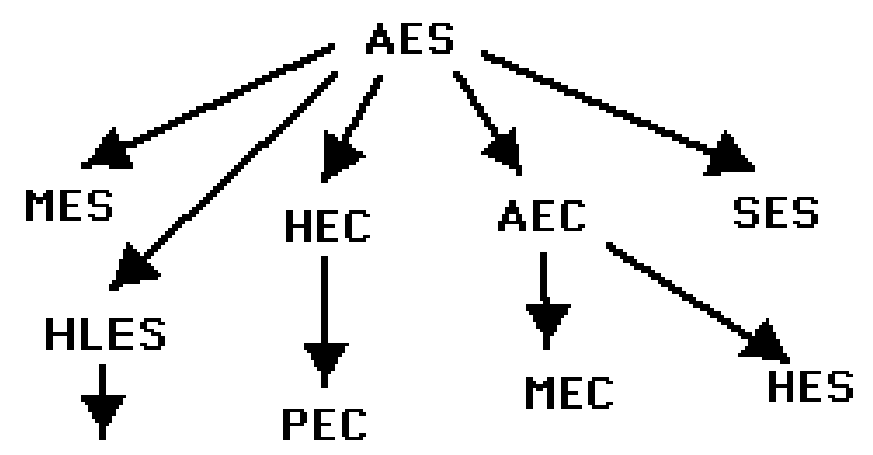

FRES

Based on Broer (2004) we have the following method of deriving the AEC from the AES:

$$
\left[\begin{array}{cc}
\mathbf{A E C} & \iota \\
\iota^{\prime} & 0
\end{array}\right]=\left[\operatorname{diag}\left(S_{1}, \ldots, S_{n}, 1\right)\left[\begin{array}{cc}
\mathbf{A E S} & \iota \\
\iota^{\prime} & 0
\end{array}\right] \operatorname{diag}\left(S_{1}, \ldots, S_{n}, 1\right)\right]^{-1}
$$

where AEC and AES are the matrices of the elasticities of complementarity and substitution and the $S_{i}$ are the cost shares. I replace the cost shares with the respective first order parameters from the translog cost function to obtain the sample mean AEC. From Syrquin and Hollender (1982) we have the following method of deriving the HEC:

$H E C_{i j}=\frac{\Sigma_{i j}}{S_{i} S_{j}}-\frac{\partial \ln \lambda}{\partial \ln y}$

where $\lambda$ is marginal cost and: 
$\Sigma=\left[\begin{array}{cc}\mathbf{A E S} & {[D \ln x / D \ln y]^{\prime}} \\ D \ln x / D \ln y & 0\end{array}\right]^{-1}$

where $D \ln x / D \ln y$ is the vector of elasticities of the factor demands with respect to output. For the translog cost function we can show that:

$\frac{\partial \ln \lambda}{\partial \ln y}=-1+\frac{\partial \ln C}{\partial \ln y}+\frac{\beta_{y y}}{\partial \ln C / \partial \ln y}$

where $\beta_{y y}$ is the coefficient of $\ln y^{2}$ in the translog function. $\partial \ln x_{i} / \partial \ln y$ is the elasticity of the demand for input $\mathrm{i}$ with respect to output $\mathrm{y}$. For the translog cost function we can also show that:

$\frac{\partial \ln x_{i}}{\partial \ln y}=\frac{\partial \ln C}{\partial \ln y}+\frac{\beta_{y i}}{S_{i}}$

where $\beta_{y i}$ is the coefficient of $\ln y$ in the relevant cost share equation. Bertoletti (2005) shows how to derive the HLES from the AES:

$H L E S_{i j}=\left(\frac{\partial \ln C}{\partial \ln y}-1\right)\left(A E S_{i j}-\frac{\partial \ln x_{i} / \partial \ln y}{\partial \ln C / \partial \ln y} \frac{\partial \ln x_{j} / \partial \ln y}{\partial \ln \lambda / \partial \ln y}\right)$

All the necessary terms have been derived above.

The MEC, PEC, FRES, and MES are easily derived from the AEC, HEC, HLES, and AES respectively as they are functions of the cross-price elasticities. By substituting the formula for the AES into that for the SES and of the AEC into that for the HES, the following expressions can be derived:

$$
\begin{aligned}
& S E S_{i j}=\frac{S_{i} S_{j}}{S_{i}+S_{j}}\left(-A E S_{i i}+2 A E S_{i j}-A E S_{j j}\right) \\
& H E S_{i j}=\frac{S_{i} S_{j}}{S_{i}+S_{j}}\left(-A E C_{i i}+2 A E C_{i j}-A E C_{j j}\right)
\end{aligned}
$$




\section{Acknowledgements}

I thank Catherine Morrison-Paul, Donald Siegel, Donald Vitaliano, James Adams, Ken Simons, Astrid Kander, Fernando de Almeida Martins and anonymous referees for very useful comments and suggestions. 


\section{References}

Allen RGD (1934) A comparison between different definitions of complementary and competitive goods. Econometrica 2:168-175

Allen RGD (1938 [1964]) Mathematical Analysis for Economists. Macmillan, London

Berndt ER, Wood DO (1975) Technology, prices and the derived demand for energy. Review of Economics and Statistics 57:259-268

Berndt ER, Wood DO (1979) Engineering and econometric interpretations of energy-capital complementarity. American Economic Review 69:342-354

Bertoletti P (2005) Elasticities of substitution and complementarity a synthesis. Journal of Productivity Analysis 24:183-196

Blackorby C, Primont D, Russell RR (2007) The Morishima gross elasticity of substitution. Journal of Productivity Analysis 28:203-208

Blackorby C, Russell RR (1975) The Partial Elasticity of Substitution. Discussion Paper 75-1, Economics, University of California, San Diego

Blackorby C, Russell RR (1981) The Morishima elasticity of substitution symmetry, constancy, separability, and relationship to the Hicks and Allen elasticities. Review of Economic Studies 43:147-158

Blackorby C, Russell RR (1989) Will the real elasticity of substitution please stand up? (A comparison of the Allen/Uzawa and Morishima elasticities). American Economic Review 79:882-888

Blumenthal T, Levhari D, Ofer G, Sheshinski E (1971) Torat HaMehirim (Price Theory, in Hebrew). Akademon, Jerusalem

Broer P (2004) The Elasticities of Complementarity and Substitution. Tinbergen Institute Discussion Paper TI 2004-101/1

Davis GC, Shumway CR (1996) To tell the truth about interpreting the Morishima elasticity of substitution. Canadian Journal of Agricultural Economics 44:173-182 
de la Grandville O (1997) Curvature and the elasticity of substitution: straightening it out. Journal of Economics 66 (1):23-34

Färe R, Primont D (1990) A distance function approach to multioutput technologies. Southern Economic Journal 56(4):879-891

Färe R, Primont D (1995) Multi-Output Production and Duality Theory and Applications. Kluwer

Frondel M, Schmidt CM (2002) The capital-energy controversy: An artifact of cost shares? The Energy Journal 23(3):53-79

Hicks, JR (1932) Theory of Wages. Macmillan, London

Hicks, JR (1936) Distribution and economic progress a revised version. Review of Economic Studies 4(1):1-12

Hicks, JR (1970) Elasticity of substitution again substitutes and complements. Oxford Economic Papers 22(3):289-296

Hicks JR, Allen RGD (1934a) A reconsideration of the theory of value, part I. Economica 1:5276

Hicks JR, Allen RGD (1934b) A reconsideration of the theory of value, part II. Economica $1: 196-219$

Hirschleifer J, Hirschleifer D (1997) Price Theory and Applications, 6th edition. Prentice Hall, Upper Saddle River NJ

Hunt LC, Lynk EL (1993) The interpretation of coefficients in multiplicative-logarithmic functions. Applied Economics 25:735-738

Kim HY (1992) The translog production function and variable returns to scale. Review of Economics and Statistics 74:546-552

Kim HY (2000) The Antonelli versus Hicks elasticity of complementary and inverse input demand systems. Australian Economic Papers 39:245-261 
Lau LJ (1978) Applications of profit functions. In: Fuss M, McFadden D (eds) Production Economics a Dual Approach to Theory and Applications, Volume 1. North-Holland, Amsterdam, pp 133-216

Lerner AP (1933) Notes on the elasticity of substitution II: The diagrammatical representation. Review of Economic Studies 1 68-70

McFadden D (1963) Constant elasticity of substitution production functions. Review of Economic Studies 31:73-83

Morishima M (1967) A few suggestions on the theory of elasticity (in Japanese). Keizai Hyoron (Economic Review) 16:144-150

Mundlak Y (1968) Elasticities of substitution and the theory of derived demand. Review of Economic Studies 35:225-236

Pigou AC (1934) The elasticity of substitution. Economic Journal 44:232-241

Robinson JV (1933) The Economics of Imperfect Competition. Macmillan, London.

Samuelson PA (1974) Complementarity: An essay on the $40^{\text {th }}$ anniversary of the Hicks-Allen revolution in demand theory. Journal of Economic Literature 12:1255-1289

Sato R, Koizumi T (1973) On the elasticities of substitution and complementarity. Oxford Economic Papers 25:44-56

Stern DI (1995) Measurement unit invariant coefficients in multiplicative-logarithmic functions. Applied Economics 27:451-454

Stern DI (2008) Derivation of the Hicks elasticity of substitution from the input distance function, Munich Personal RePEc Archive 12414.

Syrquin M, Hollender G (1982) Elasticities of substitution and complementarity the general case. Oxford Economic Papers 34:515-519

Thompson P, Taylor TG (1995) The capital-energy substitutability debate: a new look. The Review of Economics and Statistics 77:565-569

Uzawa H (1962) Production functions with constant elasticities of substitution. Review of Economic Studies 30:291-299 
Table 1. Objective and Demand Functions

\begin{tabular}{|l|l|l|l|l}
\hline \multirow{2}{*}{} & \multicolumn{2}{|l|}{ Primal } & Dual \\
\cline { 2 - 5 } & Maximization & Minimization & Maximization & Minimization \\
\hline $\begin{array}{l}\text { Objective } \\
\text { Function }\end{array}$ & $\begin{array}{l}\text { Production / } \\
\text { Output Distance }\end{array}$ & Input Distance & Profit & Cost \\
\hline $\begin{array}{l}\text { Demand } \\
\text { Function }\end{array}$ & Inverse, gross & Inverse, net & Direct, gross & Direct, net \\
\hline $\begin{array}{l}\text { Variables } \\
\text { Held } \\
\text { Constant }\end{array}$ & $\begin{array}{l}\text { price output } \\
\text { quantity inputs }\end{array}$ & $\begin{array}{l}\text { quantity output } \\
\text { quantity inputs }\end{array}$ & $\begin{array}{l}\text { price output } \\
\text { price inputs }\end{array}$ & $\begin{array}{l}\text { quantity output } \\
\text { price inputs }\end{array}$ \\
\hline
\end{tabular}


Table 2. Classification of Elasticities of Substitution and Complementarity

\begin{tabular}{|c|c|c|c|c|c|c|c|c|c|}
\hline \multirow[b]{3}{*}{ Variables } & \multirow[b]{3}{*}{$\begin{array}{l}\text { Variable } \\
\text { that Changes }\end{array}$} & \multicolumn{4}{|c|}{ Primal } & \multicolumn{4}{|l|}{ Dual } \\
\hline & & \multicolumn{2}{|c|}{ Gross } & \multicolumn{2}{|l|}{ Net } & \multicolumn{2}{|l|}{ Gross } & \multicolumn{2}{|l|}{ Net } \\
\hline & & $\begin{array}{l}\text { Name } \\
\text { of } \sigma\end{array}$ & $\begin{array}{l}\text { Held } \\
\text { Const } \\
\text { ant }\end{array}$ & $\begin{array}{l}\text { Name } \\
\text { of } \sigma\end{array}$ & $\begin{array}{l}\text { Held } \\
\text { Const } \\
\text { ant }\end{array}$ & $\begin{array}{l}\text { Name } \\
\text { of } \sigma\end{array}$ & $\begin{array}{l}\text { Held } \\
\text { Const } \\
\text { ant }\end{array}$ & $\begin{array}{l}\text { Name } \\
\text { of } \sigma\end{array}$ & $\begin{array}{l}\text { Held } \\
\text { Const } \\
\text { ant }\end{array}$ \\
\hline $\begin{array}{l}\text { Factor } \\
\text { ratio and } \\
\text { price } \\
\text { ratio }\end{array}$ & $\begin{array}{l}\text { One ratio } \\
\text { changes }\end{array}$ & & & HES & $\begin{array}{l}y, x, \\
\text { (D) }\end{array}$ & & & SES & $\begin{array}{l}\mathrm{y}, \mathrm{C}, \\
\mathrm{p}_{\mathrm{x}}\end{array}$ \\
\hline $\begin{array}{l}\text { Factor } \\
\text { ratio and } \\
\text { price } \\
\text { ratio }\end{array}$ & $\begin{array}{l}\text { One price } \\
\text { or quantity } \\
\text { changes }\end{array}$ & PEC & $\mathrm{p}_{\mathrm{y}}, \mathrm{x}$ & MEC & $y, x$ & FRES & $\mathrm{p}_{\mathrm{y}}, \mathrm{p}_{\mathrm{x}}$ & MES & $\mathrm{y}, \mathrm{p}_{\mathrm{x}}$ \\
\hline $\begin{array}{l}\text { Factor } \\
\text { quantity } \\
\text { and price }\end{array}$ & $\begin{array}{l}\text { One price } \\
\text { or quantity } \\
\text { changes }\end{array}$ & HEC & $p_{y}, x$ & AEC & $y, x$ & HLES & $\mathrm{p}_{\mathrm{y}}, \mathrm{p}_{\mathrm{x}}$ & AES & $y, p_{x}$ \\
\hline
\end{tabular}

\section{Notes:}

HES = Hicks (direct) Elasticity of Substitution (Pigou 1934)

SES $=$ Shadow Elasticity of Substitution (McFadden 1963)

PEC = Pigou Elasticity of Complementarity (Pigou 1934 and this paper)

MEC $=$ Morishima Elasticity of Complementarity (Kim 2000)

MES = Morishima Elasticity of Substitution (Morishima 1967; Blackorby and Russell 1975)

HEC $=$ Hicks Elasticity of Complementarity (Hicks 1970; Syrquin and Hollender 1982)

$\mathrm{AEC}=$ Antonelli Elasticity of Complementarity (Kim 2000)

AES = Allen Elasticity of Substitution (Hicks and Allen 1934b; Uzawa 1962).

FRES = Factor Ratio Elasticity of Substitution (Mundlak. 1968; Davis and Shumway 1996;

Blackorby et al. 2007)

HLES = Hotelling-Lau Elasticity of Substitution (Mundlak. 1968; Lau 1978; Bertoletti 2005)

$\mathrm{y}=$ output quantity, $\mathrm{p}_{\mathrm{y}}=$ output price, $\mathrm{x}=$ input quantities, and $\mathrm{p}_{\mathrm{x}}$ input prices. 


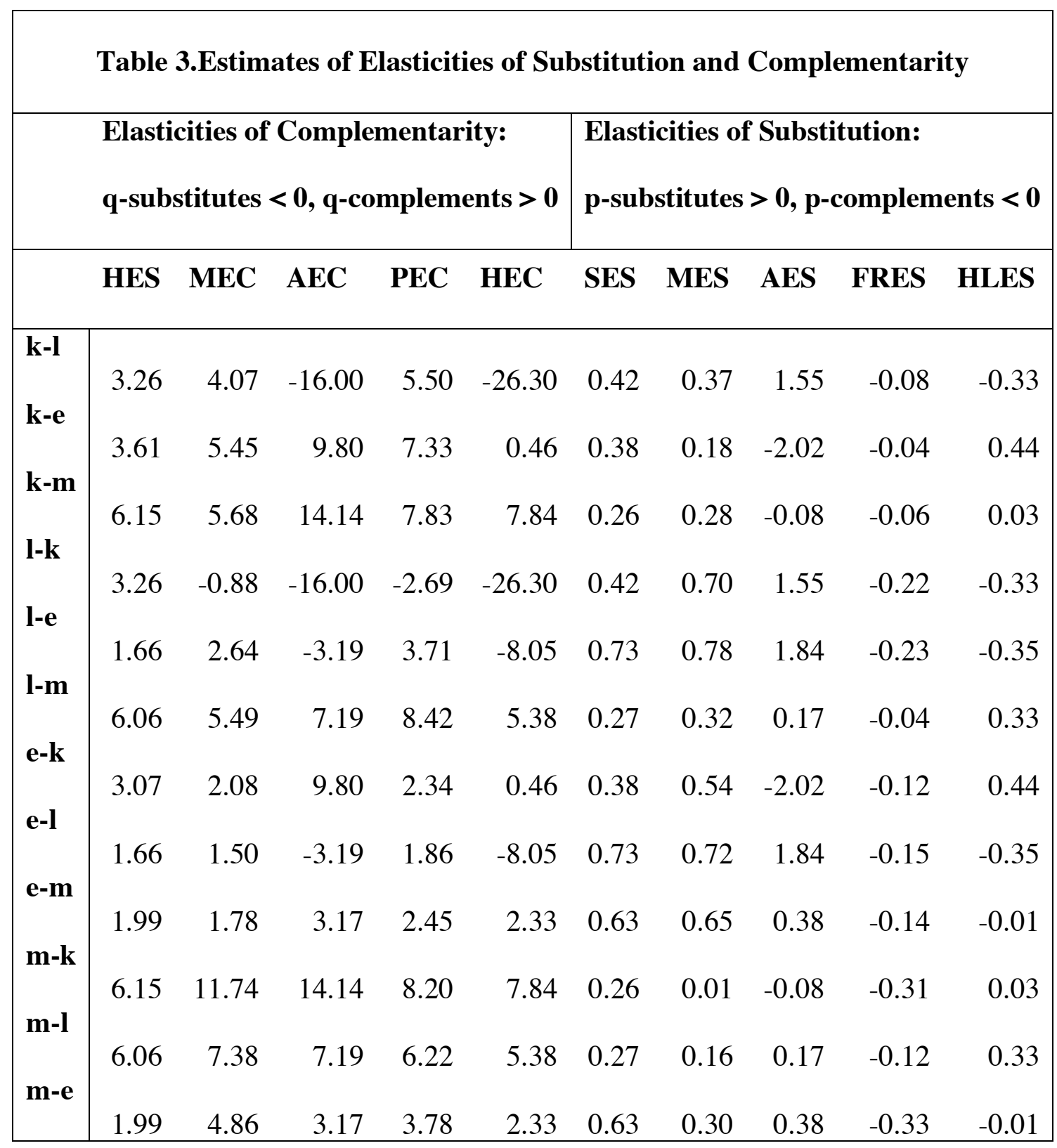

\section{Notes:}

For the non-symmetric elasticities the first input in each pair is the one whose price or quantity changes.

HES $=$ Hicks (direct) Elasticity of Substitution

SES $=$ Shadow Elasticity of Substitution

$\mathrm{PEC}=$ Pigou Elasticity of Complementarity

MEC $=$ Morishima Elasticity of Complementarity

MES = Morishima Elasticity of Substitution 
HEC = Hicks Elasticity of Complementarity
AEC = Antonelli Elasticity of Complementarity
AES = Allen Elasticity of Substitution
FRES = Factor Ratio Elasticity of Substitution
HLES = Hotelling-Lau Elasticity of Substitution 